\title{
Can the New Global Lung Initiative Equations Better Stratify the Risk of Death in Elderly People with Chronic Obstructive Pulmonary Disease?
}

\author{
Claudio Pedone ${ }^{a}$ Alessandro Di Marco Berardino ${ }^{b}$ Riccardo Pistelli ${ }^{c}$ \\ Francesco Forastiere $^{d}$ Vincenzo Bellia ${ }^{e}$ Raffaele Antonelli Incalzi ${ }^{a}$

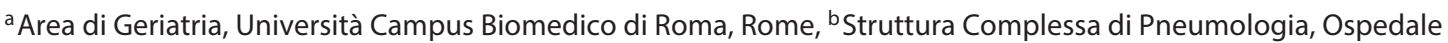 \\ S. Bassiano, Bassano del Grappa, 'Department of Respiratory Physiology, Catholic University, and d Department

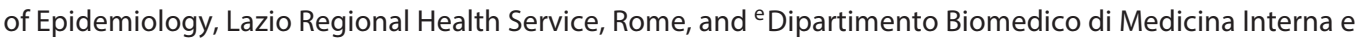 \\ Specialistica (Di.Bi.MIS), University of Palermo, Palermo, Italy
}

\section{Key Words}

Chronic obstructive pulmonary disease $\cdot$ Spirometry .

Global Lung Initiative · Prediction equations · Mortality risk

\begin{abstract}
Background: The forced expiratory volume in the first second $\left(\mathrm{FEV}_{1}\right)$ is commonly expressed as percentage of its value predicted by equations. The most commonly used equations are poorly applicable to elderly people. Recently, a set of equations (Global Lung Initiative, GLI) has been released that is expected to be more appropriate in this population. Objectives: We evaluated the agreement of the GLI, European Respiratory Society (ERS), and National Health and Nutrition Examination Survey (NHANES) equations for prediction of $\mathrm{FEV}_{1}$ and compared their discriminative capacity with respect to mortality, taking as reference the prediction equation developed in the population from which our sample was drawn (SARA). Methods: We studied 264 patients with chronic obstructive pulmonary disease aged $\geq 70$ years. Agreement was evaluated using the Bland-Altman method, discriminative capacity using incidence rate ratios for mortality calculated across quartiles of each measure. Results: The mean age of the sample was 75.8 years $(72.7 \%$ men). In women, the mean FEV1ERS/FEV1SARA, FEV1NHANES/
\end{abstract}

FEV1SARA, and FEV1GLI/FEV1SARA were $0.81,0.91$, and 0.966 , respectively. The corresponding values in men were $0.959,0.963$, and 1.02 , respectively. The overall discriminative capacity with respect to death was equally poor for all equations. Conclusion: The GLI equations for predicting $\mathrm{FEV}_{1}$ provide similar estimates compared to an equation developed in a healthy subset of the population in which they are applied, and higher values compared to the ERS equation, especially in women. However, the use of the GLI equation does not improve the stratification of the risk of mortality in elderly people compared to ERS or NHANES equations.

(c) 2016 S. Karger AG, Basel

\section{Introduction}

Despite its high prevalence [1], chronic obstructive pulmonary disease (COPD) often remains underdiagnosed and undertreated [2]. Spirometry is the fundamental examination for the diagnosis of bronchial obstruction, that is based on the ratio of the forced expiratory volume in the first second $\left(\mathrm{FEV}_{1}\right)$ and forced (www.goldcopd. com) or slow [3] vital capacity. The $\mathrm{FEV}_{1}$ is also the main parameter used to classify the severity of obstruction, and it is customary to express it as a percent of the value pre-

\section{KARGER}

E-Mail karger@karger.com

www.karger.com/res (c) 2016 S. Karger AG, Basel

0025-7931/16/0921-0016\$39.50/0
Alessandro Di Marco Berardino, MD

Struttura Complessa di Pneumologia, Ospedale S. Bassiano

Via dei Lotti, 40

IT-36031 Bassano del Grappa (Italy)

E-Mail horatio1983@libero.it 
dicted on the basis of the subject's gender, age and height $\left(\mathrm{FEV}_{1}\right.$ percent predicted, FEV1PP). $\mathrm{FEV}_{1}$ has been shown to predict mortality regardless of bronchial obstruction [4]. Predicted values are usually obtained using equations that are based on statistical assumptions (e.g., homogeneous variance of the error term of the model) that may be untenable, especially in the elderly population, introducing a significant age-related bias. Furthermore, predictions are only valid when applied to subjects that are adequately represented in the population in which the equation has been developed, and despite the advancing age of COPD patients [5], the most commonly used equations only include a relatively small fraction of elderly people. For example, the reference equations of the European Respiratory Society (ERS) [6] are only valid for people aged up to 70 years, while those based on the National Health and Nutrition Examination Survey (NHANES) [7] are valid up to 80 years of age, but included relatively few elderly people. The Global Lung Initiative (GLI) has recently issued predictive equations that cover a wide age span (3-95 years) and were developed using modern statistical techniques able to overcome some of the limits of the traditional regression models [8-10]. Accordingly, these equations should be preferred, especially in the elderly population. It is not known, however, whether FEV1PP calculated using the GLI equation can predict mortality better than FEV1PP calculated using other reference equations. The objectives of our study are to evaluate the agreement of the GLI, ERS, and NHANES equations for prediction of $\mathrm{FEV}_{1}$ with respect to a populationspecific predicting equation (SARA, Salute Respiratoria nell'Anziano - Respiratory Health in the Elderly) in a sample of people aged 70 years or older, and to compare the discriminative capacity of FEV1PP calculated using these equations with respect to 5-year mortality.

\section{Methods}

\section{Study Population and Follow-Up}

Between January 1996 and July 1999 a total of 1,970 participants were recruited from 24 Departments of Geriatrics or Respiratory Medicine within the context of the SARA study. Details on the SARA project are available elsewhere [11]. This is a multi-center Italian project investigating various aspects of chronic airway diseases in the elderly population (age $\geq 65$ years) attending pulmonary or geriatric outpatient clinics for any reason. All patients were in stable conditions when the spirometry was performed. Researchers had an extensive training in both respiratory function study of the elderly and multidimensional geriatric assessment. Enrollment was done on a consecutive basis. Data from individual centers were collected by a coordinating center at the Cattedra di
Malattie dell'Apparato Respiratorio of the University of Palermo, which was also responsible for the quality control, the retrieval and the final processing of data. The study design was approved by the Ethics Committee of the coordinating center (\#276/2012). From this dataset, we selected 904 patients aged 70 years or older with post-bronchodilator spirometry and valid anthropometric data. Of these, information on vital status as of December 2010 was available for 737 .

\section{Pulmonary Function Tests and Case Definition}

All the centers were equipped with an identical fully computerized water-sealed Stead-Wells spirometer (Baires System; Biomedin, Padua, Italy) that met the standards of the American Thoracic Society (ATS) recommendations for diagnostic spirometry. Tests were performed with a standardized technique in all centers and a quality control process was successfully implemented: all the centers achieved a high quality performance in spirometry [11]. We identified patients with COPD on the basis of presence of bronchial obstruction, defined as post-bronchodilator $\mathrm{FEV}_{1} / \mathrm{FVC}$ $<5$ th percentile measured on a subset of participants in this study without respiratory diseases or smoking exposure ( 0.65 in men and 0.67 in women) [12]. The final sample size was 264 .

\section{Analytic Approach}

We evaluated the agreement between the $\mathrm{FEV}_{1}$ predicted by the SARA equation (FEV1SARA), [13] with that predicted by the ERS (FEV1ERS) [6], NHANES (FEV1NHANES) [7], and GLI (FEV1GLI) [8] equations using the Bland-Altman method [14]. As the variance of the difference was not uniform across $\mathrm{FEV}_{1}$ values, to obtain less biased $95 \%$ agreement interval, the analysis was performed on the log scale. In this way, the difference between results obtained by the two methods compared corresponds to their ratio on the natural scale. Post-bronchodilator $\mathrm{FEV}_{1}$ was expressed as percent predicted according to FEV1SARA (FEV1PP $\left.{ }_{S A R A}\right)$, FEV1ERS (FEV1PP $\left.P_{\text {ERS }}\right)$, FEV1NHANES (FEV1PP NHANES $_{\text {, }}$, or FEV1GLI (FEV1PP GLI $)$.

To evaluate the discriminative capacity of $\mathrm{FEV}_{1}$, we estimated incidence rate ratios (IRR) for mortality calculated across quartiles of FEV1PP obtained using the different reference equations. The overall diagnostic performance was evaluated using the $\mathrm{C}$ statistic [15]. The C statistic can be interpreted in the same way as the area under the ROC curve, with higher values indicating better discriminative capacity ( 1 indicates perfect discriminative capacity). We also analyzed the agreement of the classification of patients into Global initiative on Obstructive Lung Disease (GOLD, http:// www.goldcopd.com) classes obtained using the three different reference standards. Finally, using Cox proportional hazard models, we estimated the hazard ratio for mortality across FEV1PP quartiles adjusting for other variables known to impact mortality in COPD (body mass index, dyspnea, distance covered at the 6-min walking test, and smoking exposure expressed as pack-years).

\section{Results}

The mean age of the sample was 75.8 years; men made up $72.7 \%$ of the sample. Table 1 shows the characteristics of the study sample, while the distribution of $\mathrm{FEV}_{1}$ predicted 
Fig. 1. Distribution of the $\mathrm{FEV}_{1}$ predicted by the SARA, ERS, NHANES, and GLI equations.

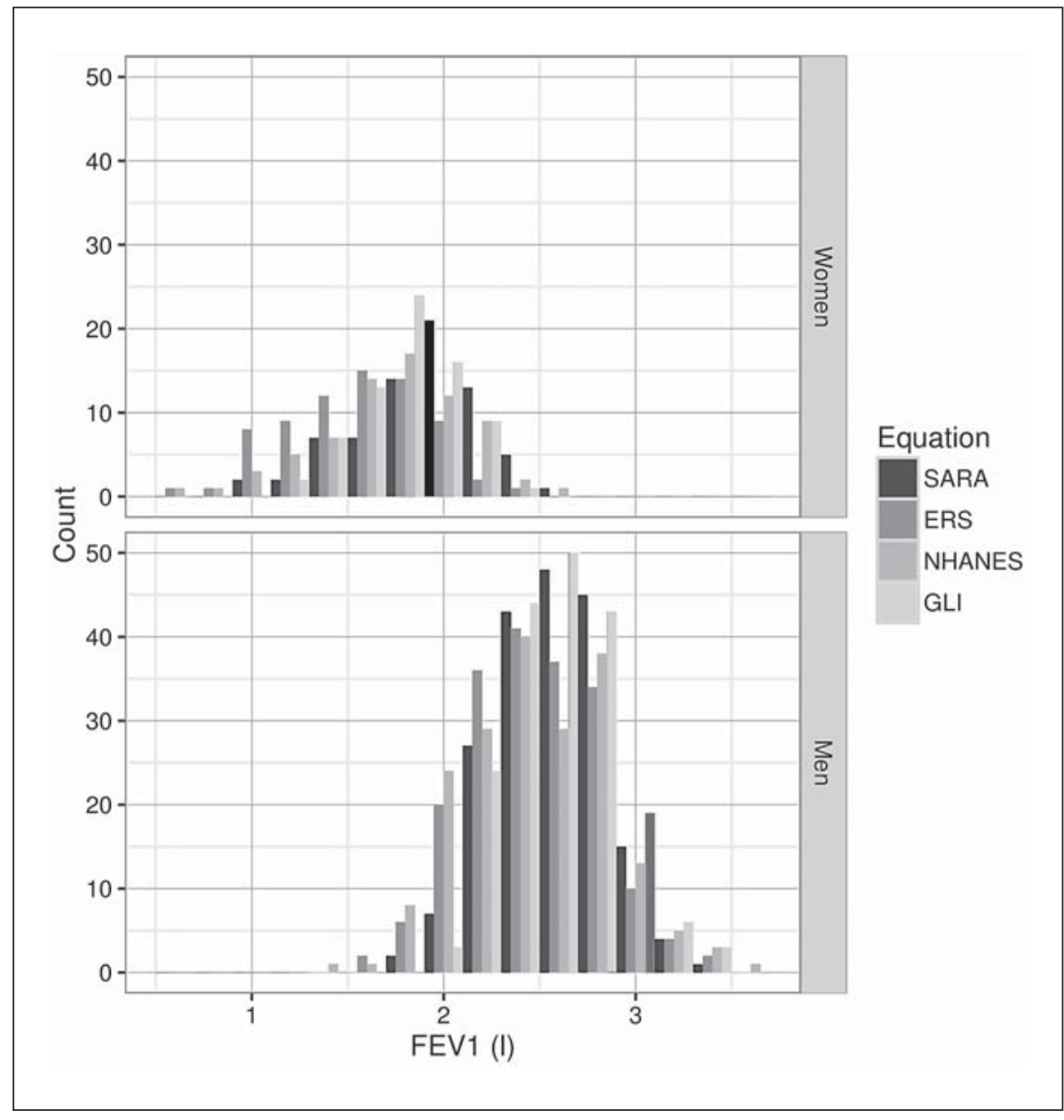

according to SARA, ERS, NHANES, and GLI is reported in figure 1 and table 2 . In our sample, 43 would not have been considered obstructed using the lower limit of normal (LLN) for $\mathrm{FEV}_{1} / \mathrm{FVC}$ based on the ERS equation, 27 using the NHANES-based LLN, and 45 using the GLI-based LLN.

In figure 2, we report the agreement between $\mathrm{FEV}_{1}$ predicted by the ERS and GLI equations. On average, the ratio between the FEV1ERS and FEV1SARA was 0.916 (95\% agreement interval: 0.765-1.097). In women, the mean ratio was 0.81 , indicating that in this group the SARA equation yields predicted values on average greater by $19 \%$ compared to the ERS equation, with $95 \%$ agreement intervals spanning from 0.683 to 0.961 . In men, there was more agreement between measures, with a mean ratio of 0.959 , indicating an average underestimation by the ERS equation of $4.1 \%$, with $95 \%$ confidence agreement between 0.908 and 1.012 .

Figure 3 shows that in general, the agreement between NHANES and SARA estimation was similar to that of
Table 1. Characteristics of the sample

Mean age $(\mathrm{SD})$, years

Men, \%

$75.8(4.9)$

73

Mean post-bronchodilator $\mathrm{FEV}_{1}$ (SD) $1.5(0.6)$

Mean Barthel index (SD)

$92.8(8.1)$

Mean pack-years smoked (SD) $\quad 35.5(35.9)$

Mean MMSE score (SD) 26.5 (3.8)

Mean GDS score (SD) $\quad 3.9$ (3.3)

Stroke, \%

Angina, \%

4

Heart failure \%

10

ERS and SARA, with a mean ratio of 0.948 (95\% agreement interval: 0.851-1.057). Compared to the ERS equation, however, in women, the NHANES estimation was in better agreement with the SARA estimation (mean ratio: 0.91 ) and with slightly less variability (95\% agreement 
Fig. 2. Bland-Altman plot showing the agreement between the ERS and SARA equations in predicting $\mathrm{FEV}_{1}$.

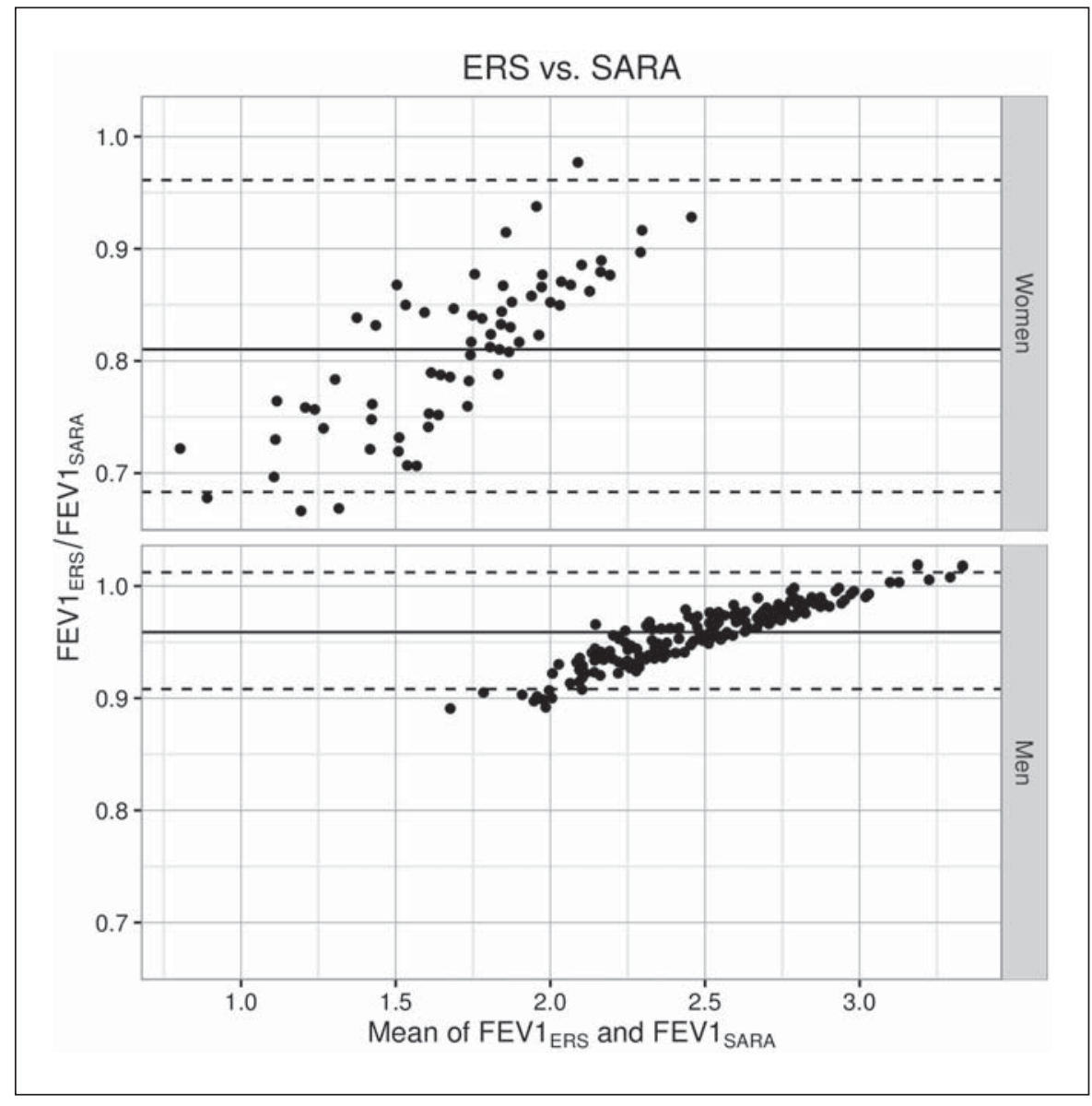

Table 2. Distribution of $\mathrm{FEV}_{1}$ percent predicted, by gender

\begin{tabular}{|c|c|c|c|c|c|c|c|c|c|c|c|c|}
\hline & \multicolumn{6}{|l|}{ Women } & \multicolumn{6}{|l|}{ Men } \\
\hline & minimum & $\begin{array}{l}\text { 1st } \\
\text { quartile }\end{array}$ & median & mean & $\begin{array}{l}\text { 3rd } \\
\text { quartile }\end{array}$ & maximum & minimum & $\begin{array}{l}\text { 1st } \\
\text { quartile }\end{array}$ & median & mean & $\begin{array}{l}3 \text { rd } \\
\text { quartile }\end{array}$ & maximum \\
\hline SARA & 0.93 & 1.71 & 1.94 & 1.89 & 2.11 & 2.55 & 1.77 & 2.35 & 2.56 & 2.56 & 2.77 & 3.3 \\
\hline ERS & 0.67 & 1.29 & 1.61 & 1.55 & 1.8 & 2.37 & 1.58 & 2.21 & 2.46 & 2.46 & 2.7 & 3.36 \\
\hline NHANES & 0.69 & 1.52 & 1.77 & 1.74 & 1.99 & 2.55 & 1.42 & 2.2 & 2.47 & 2.48 & 2.76 & 3.52 \\
\hline GLI & 1.23 & 1.64 & 1.82 & 1.82 & 2 & 2.43 & 1.93 & 2.4 & 2.59 & 2.61 & 2.81 & 3.4 \\
\hline
\end{tabular}

interval: $0.812-1.02)$. In men, the mean ratio was 0.963 (95\% CI: 0.881-1.053).

Finally, the GLI and SARA equations showed an excellent agreement overall, with a mean ratio of 1.005 and $95 \%$ agreement interval of $0.928-1.088$, with a slight underestimation in women and a slight overestimation in men (fig. 4).

New Global Lung Initiative and COPD
According to the GOLD classification system, 18.2\% participants were in class $A, 10.6 \%$ in class $B, 30.7 \%$ in class $C$, and $40.5 \%$ in class D using the SARA reference equations. Using the $\mathrm{FEV} 1 \mathrm{PP} \mathrm{P}_{E R S}, 4$ patients changed class (from $\mathrm{D}$ to $\mathrm{B}$ ), while 5 patients changed class using the FEV1PP $\mathrm{PHANES}_{\text {( }}(1$ from $\mathrm{C}$ to $\mathrm{A}$ and 4 from $\mathrm{D}$ to $\mathrm{B}$ ), and 3 using the FEV1PP ${ }_{G L I}(2$ from $\mathrm{B}$ to $\mathrm{D}$ and 1 from $\mathrm{D}$ to $\mathrm{B})$. 
Fig. 3. Bland-Altman plot showing the agreement between the NHANES and SARA equations in predicting $\mathrm{FEV}_{1}$.

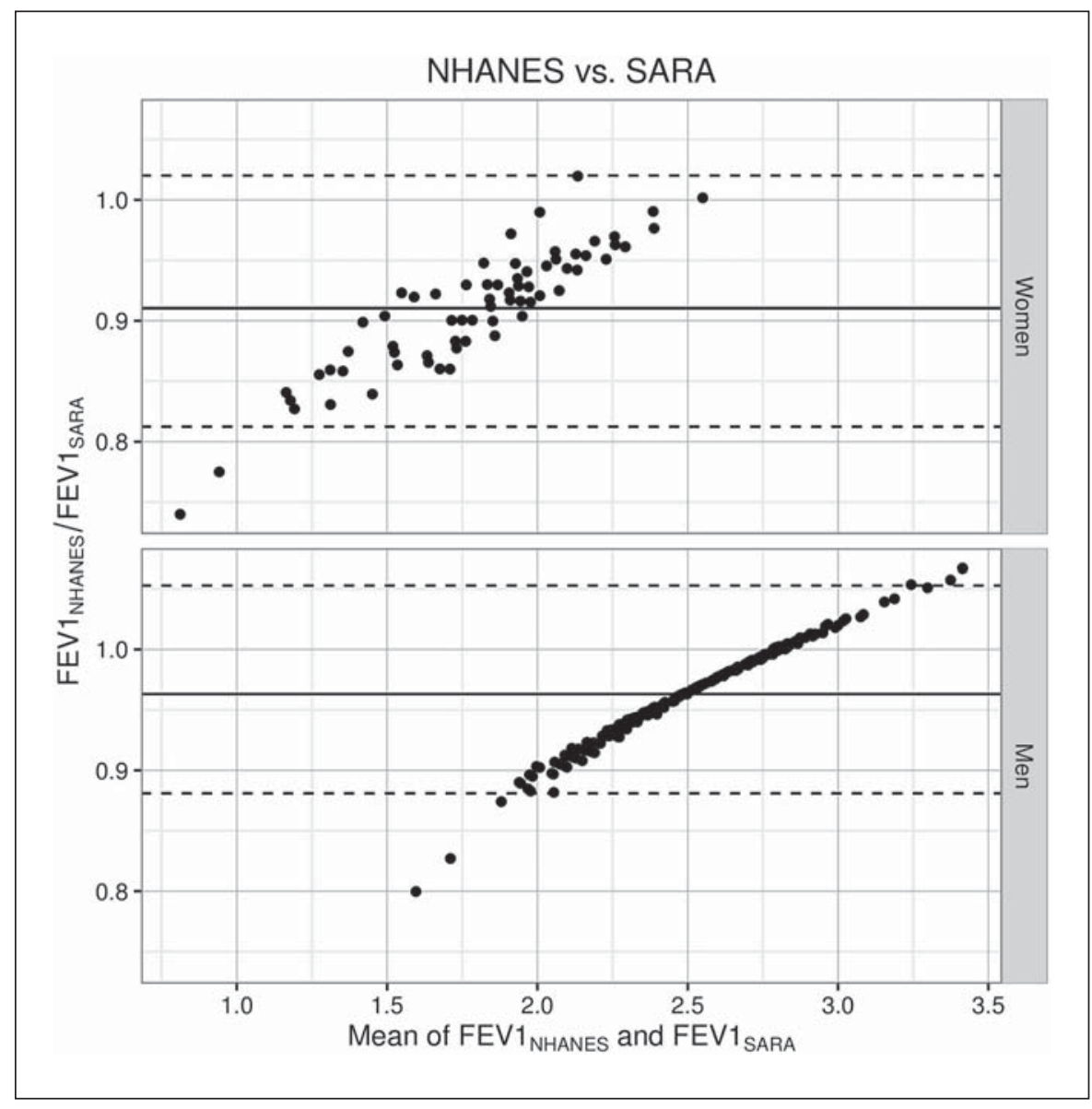

Table 3. IRR for mortality according to quartiles of $\mathrm{FEV}_{1}$ percent predicted by different standards

\begin{tabular}{lllll}
\hline & SARA & ERS & NHANES & GLI \\
\hline Best quartile & Reference & Reference & Reference & Reference \\
III quartile & $1.6(0.78-3.44)$ & $0.99(0.49-2.01)$ & $1.43(0.7-3.01)$ & $1.09(0.52-2.31)$ \\
II quartile & $2.36(1.21-4.87)$ & $1.38(0.73-2.69)$ & $2.07(1.07-4.19)$ & $1.98(1.05-3.92)$ \\
Worst quartile & $2.98(1.56-6.09)$ & $2.33(1.29-4.37)$ & $2.7(1.43-5.38)$ & $2.64(1.43-5.14)$ \\
C statistic & 0.434 & 0.419 & 0.435 & 0.425 \\
\hline
\end{tabular}

Table 3 shows that the mortality rate is increased in patients in the worst two quartiles of FEV1PP expressed according to the SARA, NHANES, and GLI equations. Using the ERS equations, instead, an increased mortality was observed only in the fourth quartile. Overall, however, the discriminative capacity was poor, as reflected by a $C$ statistic of $0.434,0.419,0.435$, and 0.425 for quartiles of $\mathrm{FEV}_{1}$ expressed as percent of SARA, ERS,
NHANES, and GLI predicted values, respectively (see also fig. 5).

After correction for body mass index, dyspnea, smoking, and distance walked at the 6-min walking test, the association between FEV1PP was weakened, and an increased risk of mortality was seen only in participants in

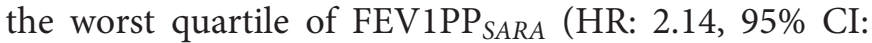
0.99-4.64) (table 4). 
Fig. 4. Bland-Altman plot showing the agreement between the GLI and SARA equations in predicting $\mathrm{FEV}_{1}$.

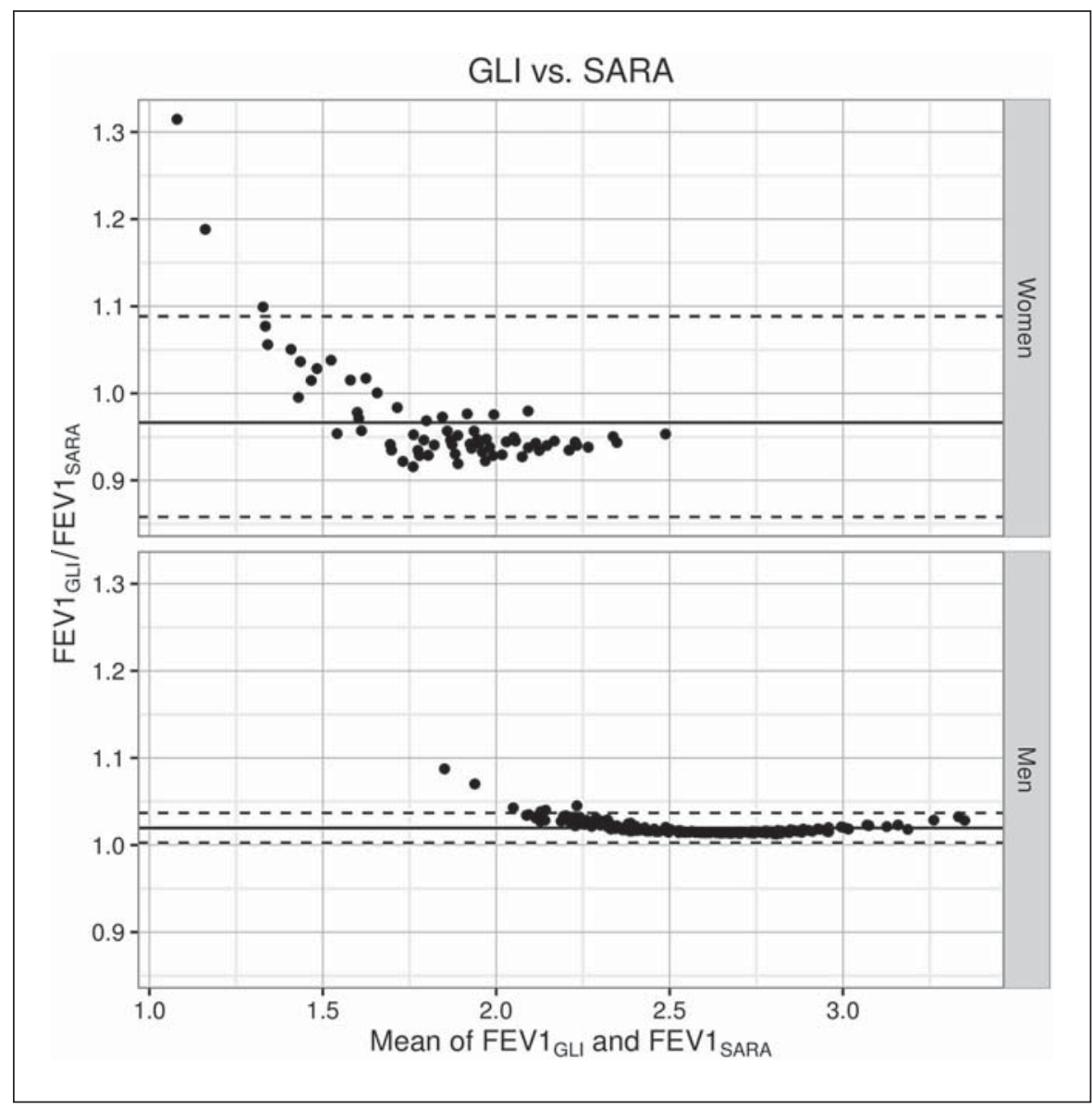

Table 4. Adjusted hazard ratio for mortality according to quartiles of $\mathrm{FEV}_{1}$ predicted by different standards

\begin{tabular}{lllll}
\hline & SARA & ERS & NHANES & GLI \\
\hline Best quartile & Reference & Reference & Reference & Reference \\
III quartile & $1.86(0.87-4.01)$ & $0.66(0.32-1.37)$ & $0.53(0.25-1.14)$ & $0.54(0.26-1.12)$ \\
II quartile & $1.77(0.83-3.77)$ & $0.66(0.32-1.37)$ & $0.85(0.41-1.79)$ & $0.61(0.29-1.26)$ \\
Worst quartile & $2.14(0.99-4.64)$ & $0.63(0.34-1.16)$ & $0.78(0.43-1.41)$ & $0.76(0.42-1.37)$ \\
\hline
\end{tabular}

Adjusted for body mass index, dyspnea, distance covered at the 6-min walking test, and exposure to cigarette smoking.

\section{Discussion}

Our data show that prediction of $\mathrm{FEV}_{1}$ according to the GLI equation has an excellent agreement with predictions made using an equation developed in a subset of our study population without respiratory diseases, which qualifies as the theoretical 'gold standard'. The agreement in women was less satisfactory compared to that in men and also had wider agreement intervals. On the opposite end, the ERS equation underestimated the theoretical $\mathrm{FEV}_{1}$ compared to the SARA equation by $9 \%$ on average and by $19 \%$ in women. The agreement between the SARA and the NHANES prediction was somewhat better, with an average underestimation of $5 \%$ overall and $9 \%$ in women. 


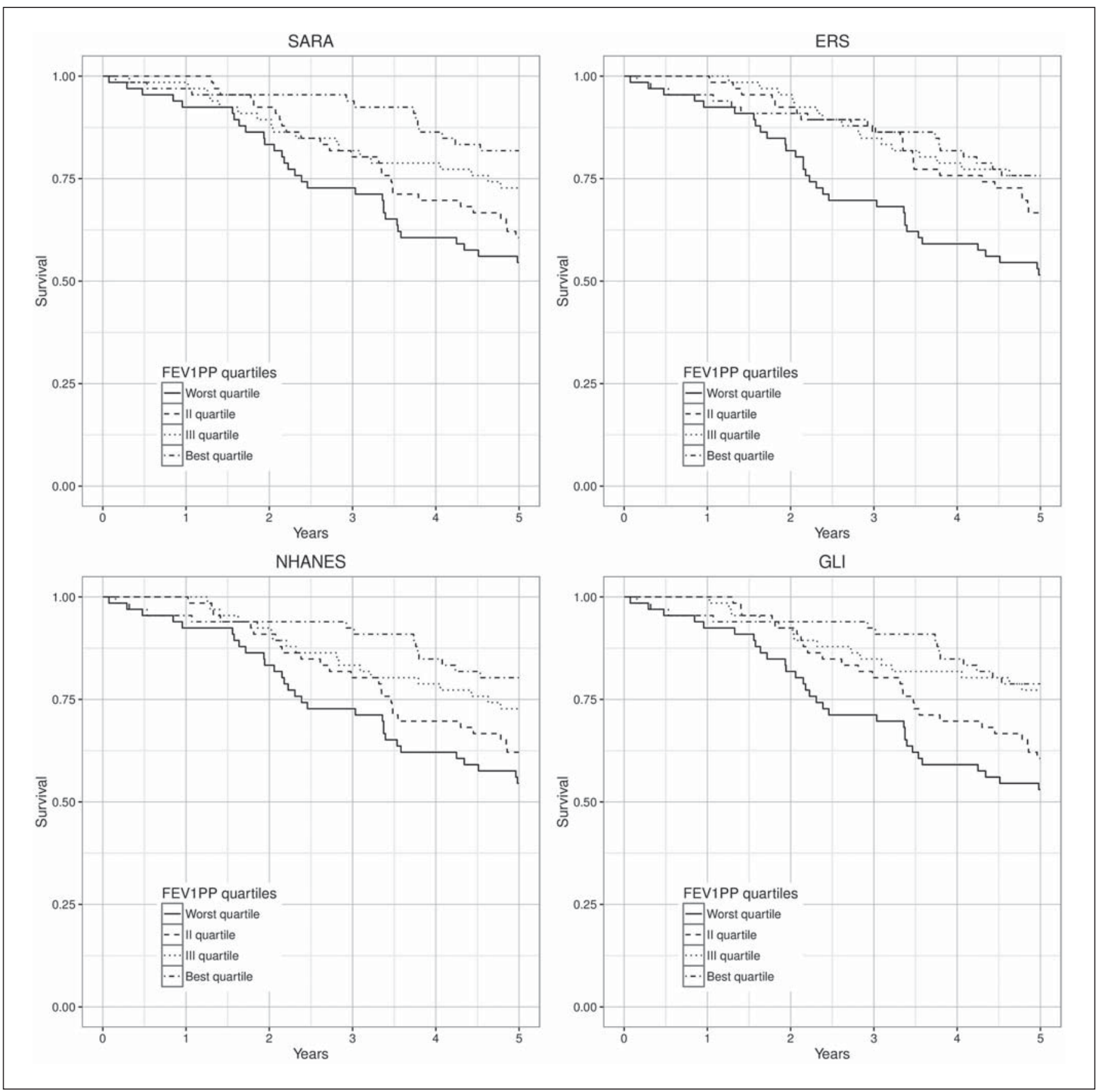

Fig. 5. Probability of surviving, by quartiles of FEV1PP.

The finding that the ERS equation yields lower values compared to the GLI equation is in contrast with the finding by Sluga et al. [16], which reported lower predicted values obtained by the GLI equation. The sample of their study, however, had a mean age of 63 years, that is, more than 10 years younger than ours. Furthermore, their ERS predicted values were corrected by a factor of 1.08 , as recommended by Dutch guidelines. On the contrary, it has repeatedly been reported that the ERS equations tend to yield lower predicted values compared to other estimat- 
ing equations, probably because of methodological issues and characteristics of the population in which the ERS equations have been developed [17-20]. This is also true for the ERS-GLI comparison: Quanjer et al. [21] reported larger predicted $\mathrm{FEV}_{1}$ compared to ERS, although the discrepancy was smaller than the one we observed. Furthermore, the difference between estimated $\mathrm{FEV}_{1}$ values was similar in men and women. It should be noted, however, that the population studied by Quanjer et al. [21] was younger, including about $50 \%$ of subjects aged $<60$ years. In the same study, in line with our results, there was little difference between the GLI and NHANES predicted values.

The clinical significance of the underestimation of $\mathrm{FEV}_{1}$ by ERS and NHANES equations deserves discussion. On the one hand, it may cause a larger proportion of patients to get treatment, especially among women, and this is relevant in the elderly population where the benefit/risk ratio of respiratory drugs tends to be smaller [22] and some of the potential side effects, such as fractures [23] or pneumonia [24], can have a dramatic impact on the health status. On the other hand, however, this overestimation is more evident at levels of $\mathrm{FEV}_{1}$ that are already relatively low, and therefore it does not necessarily change the decision about treatment. Furthermore, it is now generally accepted that the severity of COPD, and hence its treatment, should not be based only on the degree of $\mathrm{FEV}_{1}$ reduction, but also on other clinical variables. Indeed, using a severity index such as the new GOLD classification, that also takes into account symptoms and exacerbation frequency, we found no difference in staging obtained using the different equations.

The overall capacity of predicting mortality on the base of $\mathrm{FEV}_{1}$ reduction was low regardless of the reference equation used, with $C$ statistics ranging from 0.41 for
FEV 1PP $_{\text {ERS }}$ and FEV1PP $\mathrm{P}_{\text {NHANES }}$ to 0.43 for FEV1PP $G L I$. The prognostic role of FEV1PP, regardless of the equation used, is further reduced when other variables with known impact on mortality (body mass index, dyspnea, functional capacity, and smoking exposure) are taken into account. This finding was not unexpected, as it has already been shown that the predictive capacity of FEV1PP is poor compared to alternative methods to express $F E V_{1}$, such as $\mathrm{FEV}_{1}$ divided by height cubed or the $\mathrm{FEV}_{1}$ quotient, that is $\mathrm{FEV}_{1}$ divided by the sex-specific first centile of $\mathrm{FEV}_{1}[25,26]$. Our data indicate that, with respect to prognosis, the GLI equation has not overcome the problems inherent in using FEV1PP, even if known biases - especially nonconstant variability of the estimate across the whole age range - has been addressed by the statistical method used to develop these equations. A limitation of this study is that we used FVC, not VC, in the calculation of the Tiffeneau-Pinelli index. Since VC tends to be larger than FVC [27], we might have systematically overestimated the $\mathrm{FEV}_{1} / \mathrm{VC}$ ratio. Furthermore, men were over-represented, reflecting the high mean age of the sample. Since the proportion of women with COPD is increasing, this may make our results poorly generalizable to future cohorts of elderly COPD patients.

In conclusion, we showed that in elderly people with COPD, the GLI equation for predicting $\mathrm{FEV}_{1}$ provides similar estimates compared to an equation developed in a subset without respiratory diseases of the population in which they are applied, and higher values compared to the ERS equation, especially in women. However, this does not translate in different GOLD class allocations of patients. Finally, the GLI equation does not improve the stratification of the risk of mortality in elderly people with COPD with regard to the ERS or NHANES equations.

\section{References}

1 Murray CJ, Lopez AD: Alternative projections of mortality and disability by cause 1990-2020: Global Burden of Disease Study. Lancet 1997;349:1498-1504.

2 Pauwels RA, Rabe KF: Burden and clinical features of chronic obstructive pulmonary disease (COPD). Lancet 2004;364:613-620.

-3 Pellegrino R, Viegi G, Brusasco V, Crapo RO, Burgos F, Casaburi R, Coates A, van der Grinten CPM, Gustafsson P, Hankinson J, Jensen R, Johnson DC, MacIntyre N, McKay R, Miller MR, Navajas D, Pedersen OF, Wanger J. Interpretative strategies for lung function tests. Eur Respir J 2005;26:948-968.
4 Hole DJ, Watt GC, Davey-Smith G, Hart CL, Gillis CR, Hawthorne VM: Impaired lung function and mortality risk in men and women: findings from the Renfrew and Paisley prospective population study. BMJ 1996;313: 711-715; discussion 715-716.

5 Halbert RJ, Isonaka S, George D, Iqbal A: Interpreting COPD prevalence estimates: what is the true burden of disease? Chest 2003;123: 1684-1692.

-6 Quanjer PH, Tammeling GJ, Cotes JE, Pedersen OF, Peslin R, Yernault JC: Lung volumes and forced ventilatory flows. Eur Respir J 1993;6(suppl 16):5-40.
Hankinson JL, Odencrantz JR, Fedan KB: Spirometric reference values from a sample of the general U.S. population. Am J Respir Crit Care Med 1999;159:179-187.

8 Quanjer PH, Stanojevic S, Cole TJ, Baur X, Hall GL, Culver BH, Enright PL, Hankinson JL, Ip MSM, Zheng J, Stocks J: ERS Global Lung Function Initiative. Multi-ethnic reference values for spirometry for the 3-95-yr age range: the global lung function 2012 equations. Eur Respir J 2012;40:1324-1343. 
-9 Brazzale DJ, Hall GL, Pretto JJ: Effects of adopting the new global lung function initiative 2012 reference equations on the interpretation of spirometry. Respiration 2013;86: 183-189.

10 Caramori G, Paredi P: Global lung function standardisation: finally making our dream a reality? Respiration 2013;86:179-180.

-11 Bellia V, Pistelli R, Catalano F, Antonelli-Incalzi R, Grassi V, Melillo G, Olivieri D, Rengo F: Quality control of spirometry in the elderly - the SARA study. Am J Respir Crit Care Med 2000;161:1094-1100.

12 Sorino C, Battaglia S, Scichilone N, Pedone C, Antonelli-Incalzi R, Sherrill D, Bellia V: Diagnosis of airway obstruction in the elderly: contribution of the SARA study. Int J Chron Obstruct Pulmon Dis 2012;7:389-395.

13 Pistelli R, Bellia V, Catalano F, Antonelli Incalzi R, Scichilone N, Rengo F; SARA Study Group. Spirometry reference values for women and men aged 65-85 living in southern Europe: the effect of health outcomes. Respiration 2003;70:484-489.

14 Bland JM, Altman DG: Statistical methods for assessing agreement between two methods of clinical measurement. Lancet 1986;1:307-310.

15 Harrell FE: Regression Modeling Strategies (corrected ed). New York, Springer, 2001.
16 Sluga R, Smeele IJM, Lucas AE, Thoonen BP, Grootens-Stekelenburg JG, Heijdra YF, Schermer TR: Impact of switching to new spirometric reference equations on severity staging of airflow obstruction in COPD: a crosssectional observational study in primary care. Prim Care Respir J 2014;23:85-91.

17 Kuster SP, Kuster D, Schindler C, Rochat MK, Braun J, Held L, Brändli O: Reference equations for lung function screening of healthy never-smoking adults aged 18-80 years. Eur Respir J 2008;31:860-868.

18 Roca J, Burgos F, Sunyer J, Saez M, Chinn S, Antó JM, Rodríguez-Roisin R, Quanjer $\mathrm{PH}$, Nowak D, Burney P: References values for forced spirometry. Group of the European Community Respiratory Health Survey. Eur Respir J 1998;11:1354-1362.

19 Langhammer A, Johnsen R, Gulsvik A, Holmen TL, Bjermer L: Forced spirometry reference values for Norwegian adults: the Bronchial Obstruction in Nord-Trøndelag Study. Eur Respir J 2001;18:770-779.

20 Falaschetti E, Laiho J, Primatesta P, Purdon S: Prediction equations for normal and low lung function from the Health Survey for England. Eur Respir J 2004;23:456-463.

21 Quanjer PH, Brazzale DJ, Boros PW, Pretto JJ: Implications of adopting the Global Lungs
Initiative 2012 all-age reference equations for spirometry. Eur Respir J 2013;42:1046-1054.

22 Valente S, Pasciuto G, Bernabei R, Corbo GM: Do we need different treatments for very elderly COPD patients? Respiration 2010;80: 357-368.

23 Loke YK, Cavallazzi R, Singh S: Risk of fractures with inhaled corticosteroids in COPD: systematic review and meta-analysis of randomised controlled trials and observational studies. Thorax 2011;66:699-708.

24 Kew KM, Seniukovich A: Inhaled steroids and risk of pneumonia for chronic obstructive pulmonary disease. Cochrane Database Syst Rev 2014;3:CD010115.

25 Miller MR, Pedersen OF: New concepts for expressing forced expiratory volume in $1 \mathrm{~s}$ arising from survival analysis. Eur Respir J 2010;35:873-882.

26 Pedone C, Scarlata S, Scichilone N, Forastiere F, Bellia V, Antonelli-Incalzi R: Alternative ways of expressing FEV1 and mortality in elderly people with and without COPD. Eur Respir J 2013;41:800-805.

27 Yuan W, He X, Xu QF, Wang HY, Casaburi $\mathrm{R}$ : Increased difference between slow and forced vital capacity is associated with reduced exercise tolerance in COPD patients. BMC Pulm Med 2014;14:16. 